\title{
Development and Implementation of a Collective Teacher Efficacy Scale Among Elementary School Homeroom Teachers
}

\author{
Chia-Hsun Chiang \\ National Sun Yat-sen University, Kaohsiung, Taiwan \\ Wan-Chen Hsu \\ National Kaohsiung Normal University; \\ National Kaohsiung University of Applied Sciences, Kaohsiung, Taiwan \\ Hsueh-Hua Chuang \\ Iowa State University, Ames, USA; \\ National Sun Yat-sen University, Kaohsiung, Taiwan
}

\begin{abstract}
Collective teacher efficacy has been a prominent research topic in the field of educational effectiveness. Improving the quality of scales measuring collective teacher efficacy is imperative. The aims of this study were to revise a self-report Collective Teacher Efficacy Scale (CTES), and investigate the relationship between collective teacher efficacy and teacher self-efficacy among elementary school homeroom teachers in Taiwan. A nationally representative sample of 758 elementary school homeroom teachers from 57 schools was recruited for the study. First, the structural equation modeling results revealed that the CTES, which contains questions about teachers' perceptions of student discipline and instructional strategies, is a reliable and valid measure. Second, elementary school homeroom teachers perceived themselves to have positive teacher self-efficacy and positive collective teacher efficacy in their schools. Finally, collective teacher efficacy was positively correlated with teacher self-efficacy. Discussion of the results and recommendations for future research were also provided.
\end{abstract}

Keywords: collective teacher efficacy, elementary school teachers, teacher self-efficacy, quantitative research

\section{Introduction}

Collective teacher efficacy differs from teacher self-efficacy in that it refers to teacher perception of the effectiveness of the teaching staff as a whole, rather than teacher judgments of the effectiveness of individual teachers (Goddard, Hoy, \& Hoy, 2004). Previous studies have reported that teacher self-efficacy is related to teaching behavior in the classroom (Abu-Tineh, Khasawneh, \& Khalaileh, 2011; Hsiao, Chang, Tu, \& Chen, 2011; Rahimi \& Gheitasi, 2010). Bandura (1997) argued that the collective efficacy of the teachers within a school is a powerful construct that varies considerably among schools and is systematically associated with student achievement. Therefore, collective teacher efficacy has been considered a vital predictor of the

Chia-Hsun Chiang, Ph.D., Institute of Education, National Sun Yat-sen University.

Wan-Chen Hsu, post-doctoral fellow, Graduate Institute of Adult Education, National Kaohsiung Normal University; Center for Teaching and Learning Development, National Kaohsiung University of Applied Sciences.

Hsueh-Hua Chuang, Ph.D., associate professor, Department of Curriculum and Instruction, Iowa State University; Institute of Education/Center for Teacher Education, National Sun Yat-sen University. 
differences in teacher self-efficacy and teaching behavior.

Teachers used their sense of efficacy in order to be effective in teaching (Magno \& Sernbrano, 2007). Collective teacher efficacy has been a prominent research topic in the field of educational effectiveness. It is associated with teachers' self-efficacy, motivation, and teaching ability as well as student learning outcomes (Lee, Zhang, \& Yin, 2011). Several studies have indicated that collective teacher efficacy can positively affect teachers' self-efficacy (e.g., Chen \& Wu, 2010; Goddard et al., 2004; Hung, 2010; Skaalvik \& Skaalvik, 2007) and teaching behavior (e.g., Chiang, 2014; Ciani, Summers, \& Easter, 2008) in addition to their students' learning achievement (e.g., Bandura, 1997; Goddard \& Goddard, 2001; Tschannen-Moran \& Barr, 2004).

Improving the quality of scales measuring collective teacher efficacy is imperative. For some of such scales, only one factor can be extracted through factor analysis (e.g., Barr, 2002; Goddard, 1999; 2002). In addition, follow-up studies have not been conducted to verify the applicability or suitability of the measurement models that underlie the scales. Therefore, developing a highly valid self-report instrument for measuring teachers' collective teacher efficacy is necessary. Accordingly, the objective of the current study was to develop a Collective Teacher Efficacy Scale (CTES) that involves applying Teacher Self-Efficacy Scale (TSES) as a criterion for understanding the relationship between collective teacher efficacy and self-efficacy.

\section{Literature Review}

\section{Meaning of Collective Teacher Efficacy}

Collective teacher efficacy, which is defined as teachers' perception that the educational efforts of the faculty as a whole have a positive effect on students, is based on Bandura's $(1977 ; 1997)$ social cognitive theory. Social cognitive theory acknowledges that "personal agency operates within a broad network of socio-structural influences" (Bandura, 1997, p. 6), meaning that perceived levels of ability in any specific situation are mediated by the social interaction norms prevailing in that situation (Tschannen-Moran, Hoy, \& Hoy, 1998). The theory therefore extends the analysis of the mechanisms of human agency to the exercise of collective agency (Bandura, 1997), which is the shared belief that people can make a difference by working together.

Bandura (2000) defined collective efficacy as "people's shared beliefs in their collective power to produce desired results" (p. 75). When a group of individuals engages in a common endeavor, success depends on the individual capabilities of each member and their ability to pool resources, communicate clearly, and coordinate their efforts. For schools, collective teacher efficacy refers to teachers' expectations about the effectiveness of the school and to their collective perceptions and beliefs about how to effectively organize and execute teaching functions to make a positive educational difference for the students (Demir, 2008; Goddard \& Goddard, 2001; Goddard, Hoy, \& Hoy, 2000; Goddard et al., 2004; Moolenaar, Sleegers, \& Daly, 2012).

Collective teacher efficacy is based on individual teachers' perceptions of the capabilities of the entire group (Lim \& Eo, 2014). Several researchers have employed individually perceived collective teacher efficacy to assess the criterion validity of the CTES they have developed (e.g., Goddard, 1999; Goddard et al., 2000). Other researchers have examined the relationship between individually perceived collective teacher efficacy and other variables, such as teacher efficacy and teacher commitment (e.g., Gibbs \& Powell, 2012; Lee et al., 2011; Skaalvik \& Skaalvik, 2007). The present study addressed individually perceived levels of collective efficacy with no aggregation. 
In recent years, studies have reported that collective teacher efficacy comprises two dimensions. Goddard et al. (2000) proposed two dimensions of assessment of teaching competence and the challenges presented by the teaching task in a particular school. The challenges include the availability of school-provided resources, presence of community resources and constraints, and physical facilities of the campus. Teaching competence encompasses teaching students learning skills, level of training, and years of experience. Several researchers have adopted these two dimensions to measure teachers' collective teacher efficacy in empirical studies (e.g., Fives \& Looney, 2009; Goddard et al., 2004; Ross \& Gray, 2006).

Barr (2002) proposed two other dimensions of collective teacher efficacy: student discipline and instructional strategies. Student discipline is a faculty's collective capability to manage student behavior. Instructional strategies are a faculty's collective capability to promote student learning. This scheme differs from the previous one in emphasizing student discipline. Several researchers have adopted these two dimensions for measuring teachers' collective teacher efficacy in empirical studies (e.g., Chen, 2010; Chen \& Wu, 2010; Lee et al., 2011; Tschannen-Moran \& Barr, 2004).

Self-efficacy is a multidimensional construct (Tschannen-Moran et al., 1998), and collective efficacy is rooted in self-efficacy (Bandura, 1997). The two dimensions proposed by Barr (2002) have a very important impact on student achievement (Chen, 2009; Chiang, 2014). Accordingly, in developing our measurement model, we defined collective teacher efficacy as consisting of the two dimensions proposed by Barr (2002).

\section{Review of Instruments Measuring Collective Teacher Efficacy}

In this study, we developed a self-report instrument that can be used to accurately measure teachers' collective teacher efficacy on the basis of the two dimensions of instructional strategies and student discipline. Only one factor could be extracted from the previous scales through factor analysis (e.g., Barr, 2002; Goddard, 1999; 2002). For example, Goddard (1999) adhered to the theoretical model proposed by Tschannen-Moran et al. (1988) and adapted the two-factor scale of Gibson and Dembo (1984). Goddard (1999) extracted one factor and the Cronbach's $\alpha$ was 0.96 .

Goddard (2002) adapted the scale of Goddard (1999) to create the short form of our scale, called the Collective Teacher Efficacy Instrument-Short Form (CTEI-SF). The CTEI-SF (12 items) is more theoretically pure than the original CTEI (21 items). The correlation $r$ between CTEI-SF and the CTEI was 0.98. Goddard extracted one dimension for the CTEI-SF, and Cronbach's $\alpha$ was 0.94 .

Barr (2002) used the Collective Teacher Belief Scale (CTBS), which has two subscales: instructional strategies (six items) and student discipline (six items). However, Barr extracted only one factor, with the Cronbach $\alpha$ value of 0.90 , through factor analysis.

In short, both the CEI-SF and CTBS have only one factor. Follow-up studies have not been conducted to verify the applicability or suitability of the models for these scales. Therefore, we developed our own self-report instrument that can be used to accurately measure teachers' collective teacher efficacy (defined by instructional strategies and student discipline) and to explore its measurement model.

\section{Teacher Self-Efficacy and Collective Teacher Efficacy}

According to Bandura's (1986) social cognitive theory, self-efficacy refers to individuals' beliefs about their own ability to successfully implement a particular course of action. In reference to schools, teachers assess their own ability to bring about desired outcomes of student engagement and learning. This assessment is a 
teacher's self-efficacy (Chen, 2009; Hsu, 2008; Tschannen-Moran \& Hoy, 2001). Bandura (1997) argued that collective efficacy is rooted in self-efficacy.

Skaalvik and Skaalvik (2007) emphasized that individual teachers' self-efficacy might depend on how adequately the team to which the teacher belongs functions. Teachers do not always work alone. In Taiwanese schools, most of the organizing and planning functions are chosen and conducted by teachers. Homeroom teachers and subject teachers work as a team, sharing responsibility for each class of students. In such cases, a correlation between collective teacher efficacy and teacher self-efficacy can be expected. Research on teachers' senses of self-efficacy indicates that self-efficacy is positively associated with collective efficacy (e.g., Calik, Sezgin, Kavgaci, \& Cagatay Kilinc, 2012; Gibbs \& Powell, 2012; Goddard \& Goddard, 2001). Accordingly, we propose the following hypothesis: A teacher's self-efficacy is positively associated with collective efficacy.

\section{Method}

This study was reviewed and approved by the Institutional Review Board (IRB) at the Institute of Education at National Sun Yat-sen University before it began. Professor Shu-Ching Yang, Professor Chin-Tang Tu, Professor Ching-Lin Shih, and Professor Wen Cheng were on the IRB/ethics committee that approved the study. Informed consent was obtained from each participant before joining our study.

\section{Participants}

Sample for the pilot study. For the pilot study, a purposive sample of 232 homeroom teachers was drawn from 16 public elementary schools in Taiwan. Each participant was mailed a questionnaire, and 224 usable (complete) questionnaires were returned, resulting in an effective response rate of $96.55 \%$.

Sample for the formal study. We employed a stratified cluster sampling method. We used region as the tier basis and school as the sampling unit and determined the optimal sample size for each region according to the proportion of elementary school homeroom teachers in the northern, central, southern, and eastern regions of Taiwan.

We recruited 877 teachers from 57 elementary schools to participate in our survey. Respondents who had not completed the entire survey or who provided invalid responses were removed, and a total of 758 valid surveys (86.43\%) were retained, an acceptable response rate. Among these 758 valid respondents, 289 (38.13\%) respondents taught in the northern region of Taiwan, $213(28.10 \%)$ taught in the central region of Taiwan, 213 $(28.10 \%)$ taught in the southern region of Taiwan, and 43 (5.67\%) taught in the eastern region of Taiwan.

\section{Instruments}

CTES. As mentioned, the objective of this study was to develop a self-report instrument that can be used to accurately measure teachers' collective teacher efficacy according to the two dimensions of student discipline and instructional strategies. The 11-item CTES, which we developed following a thorough literature review (e.g., Chen, 2009; Hung, Chiou, \& Huang, 2012; Tschannen-Moran \& Barr, 2004) and applying the process of concept clarification, comprises two subscales with the same names as the dimensions they measure: student discipline (five items) and instructional strategies (six items). The respondents answered the items by using a 5-point Likert scale with scores ranging from 1 ("Not at all") to 5 ("A great deal").

Item analyses returned $t$ values ranging between 7.10 and 16.21 (all $p<0.001$ ), demonstrating adequate discrimination of the responses. According to the results of inter item correlations $(0.35<r<0.83$, all $p<$ 0.001 ) and a homogeneity test, all items were retained. Finally, an exploratory factor analysis (principal axis 
factoring extraction; eigenvalue $>1$ ) revealed that the value of the Kaiser-Meyer-Olkin (KMO) test was 0.84 $\left(\chi^{2}=1333.40 ; d f=55 ; p<0.001\right)$, Bartlett's sphericity test was significant $(p<0.05)$, and the explained variance was $54.29 \%$. The high Cronbach $\alpha$ coefficients $(0.89$ for student discipline, 0.82 for instructional strategies, and 0.92 for the total scale) demonstrated high internal consistency. Table 1 shows the CTES items.

Table 1

CTES Definitions and Item Content

\begin{tabular}{|c|c|c|c|}
\hline Subscales & Definition & Item content & Source(s) \\
\hline \multirow{5}{*}{$\begin{array}{l}\text { Student } \\
\text { discipline }\end{array}$} & \multirow{5}{*}{$\begin{array}{l}\text { The perception of } \\
\text { teachers in a } \\
\text { school of how } \\
\text { well the efforts } \\
\text { of the faculty as a } \\
\text { whole manage } \\
\text { student behavior } \\
\text { and discipline. }\end{array}$} & $\begin{array}{l}\text { How well do teachers in your school construct rules to promote students' } \\
\text { learning? }\end{array}$ & \multirow{5}{*}{$\begin{array}{l}\text { Chen (2009); Hung } \\
\text { et al. (2012); and } \\
\text { Tschannen-Moran } \\
\text { and Barr (2004) }\end{array}$} \\
\hline & & How well do teachers in your school get students to follow school rules? & \\
\hline & & How well do school personnel in your school control disruptive behavior? & \\
\hline & & $\begin{array}{l}\text { How well does your school help students perform well while they are at } \\
\text { school? }\end{array}$ & \\
\hline & & How well do teachers in your school teach students proper etiquette? & \\
\hline \multirow{6}{*}{$\begin{array}{l}\text { Instructional } \\
\text { strategies }\end{array}$} & \multirow{6}{*}{\begin{tabular}{|l|} 
The perceptions \\
of teachers in a \\
school that the \\
efforts of the \\
faculty as a \\
whole promote \\
student learning.
\end{tabular}} & How well do teachers in your school use multiple assessments? & \multirow{6}{*}{$\begin{array}{l}\text { Chen (2009); Hung } \\
\text { et al. (2012); and } \\
\text { Tschannen-Moran } \\
\text { f and Barr (2004) } \\
\end{array}$} \\
\hline & & How well do teachers in your school help students master content? & \\
\hline & & How well do teachers in your school help students think critically? & \\
\hline & & $\begin{array}{l}\text { How well do teachers in your school provide different examples and } \\
\text { explanations in their teaching? }\end{array}$ & \\
\hline & & $\begin{array}{l}\text { How well do teachers in your school promote deep understanding of } \\
\text { academic concepts? }\end{array}$ & \\
\hline & & $\begin{array}{l}\text { How well do teachers in your school adopt individualized instruction based } \\
\text { on evaluation? }\end{array}$ & \\
\hline
\end{tabular}

TSES. The 12-item TSES, which we developed following a thorough literature review (e.g., Chen, 2009; Hsu, 2008; Tschannen-Moran \& Hoy, 2001) and employing the process of concept clarification, contains three subscales: efficacy of classroom management (four items), efficacy of student engagement (four items), and efficacy of instructional strategies (four items). The items were answered using a 5-point Likert scale with scores ranging from 1 ("Not at all") to 5 ("A great deal").

Item analyses revealed $t$ values ranging between 7.21 and 11.83 (all $p<0.001$ ), demonstrating adequate discrimination of the responses. According to inter item correlations $(0.20<r<0.72$, all $p<0.01)$ and a homogeneity test, all items were retained. Finally, an exploratory factor analysis (principal axis factoring extraction; eigenvalue $>1)$ revealed that the KMO test value was $0.89\left(\chi^{2}=1,241.38 ; d f=66 ; p<0.001\right)$, Bartlett's sphericity test was significant $(p<0.05)$, and the explained variance was $67.22 \%$. The high Cronbach $\alpha$ coefficients ( 0.87 for efficacy of classroom management, 0.83 for efficacy of student engagement, 0.74 for efficacy of instructional strategies, and 0.88 for the total scale) demonstrated high internal consistency. Table 2 shows the TSES items.

\section{Data Analysis}

First, peer review was used to confirm the content validity of the CTES and TSES. Second, item analysis and exploratory factor analysis were used to assess the validity and reliability of these scales. Third, confirmatory factor analysis was used to identify the optimal measurement models for the CTES. Fourth, the means and standard deviations of both scales were calculated to describe the current levels of collective teacher efficacy and teacher self-efficacy. Finally, Pearson product-moment correlations were used to analyze the relationship between scores on the CTES, the TSES, and their respective subscales. 
Table 2

TSES Item Content

\begin{tabular}{|c|c|}
\hline Subscales & Item content \\
\hline Efficacy of classroom management & $\begin{array}{l}\text { 1. How well do you control disruptive behavior in the classroom? } \\
\text { 2. How well do you get children to follow classroom rules? } \\
\text { 3. How well do you calm a student who is disruptive or noisy? } \\
\text { 4. To what extent do you use multiple management strategies? }\end{array}$ \\
\hline Efficacy of student engagement & $\begin{array}{l}\text { 5. How well do you maintain the students' concentration in class? } \\
\text { 6. How well do you create a pleasant learning atmosphere in class? } \\
\text { 7. How well do you motivate students who show low interest in schoolwork? } \\
\text { 8. How well do you improve the understanding of a student who is failing? }\end{array}$ \\
\hline Efficacy of instructional strategies & $\begin{array}{l}\text { 9. To what extent do you use multiple assessment strategies? } \\
\text { 10. To what extent do you provide an alternative explanation or example when students are } \\
\text { confused? } \\
\text { 11. To what extent do you use multiple instructional strategies? } \\
\text { 12. How well do you adjust your lessons to the proper levels for individual students? }\end{array}$ \\
\hline
\end{tabular}

\section{Results}

\section{Confirmatory Factor Analysis}

According to the reference standard of Bagozzi and Yi (1988), we used the preliminary fit, overall model fit, and fit of the internal structural model as criteria to examine our measurement model (see Figure 1).

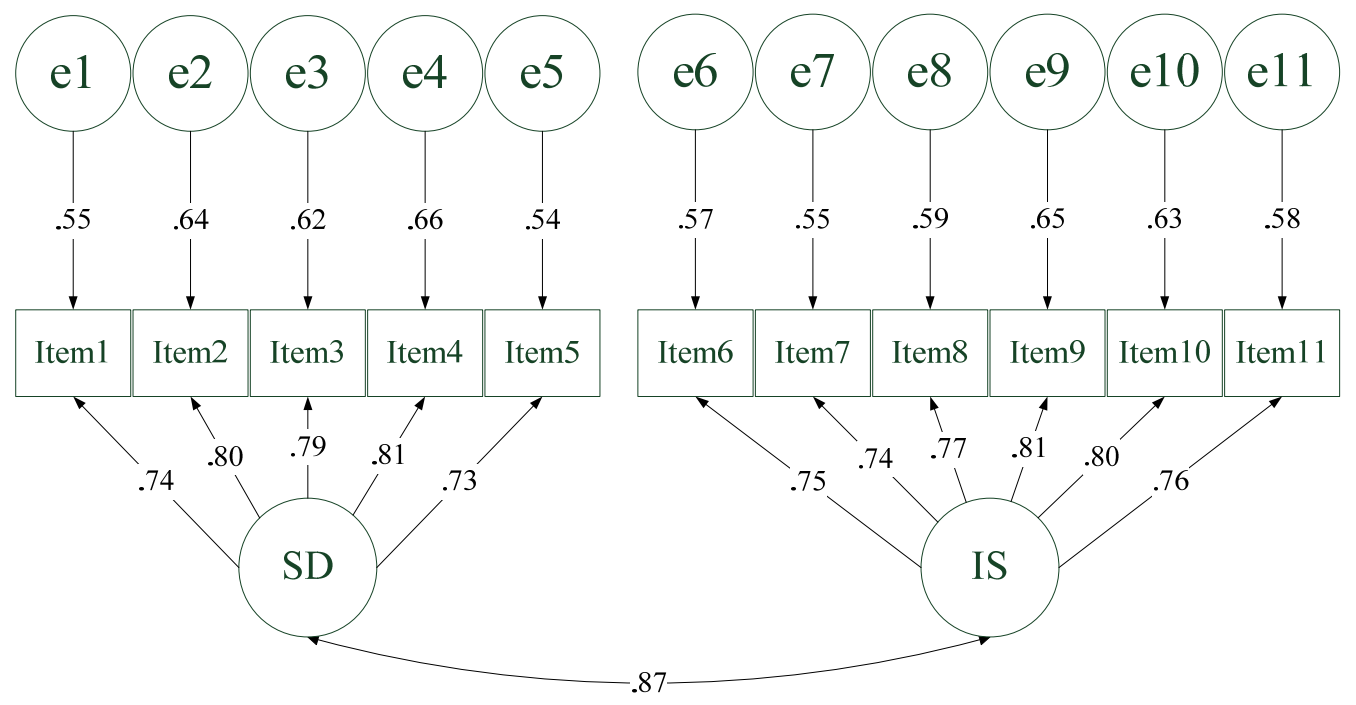

Figure 1. Measurement model for the CTES.

Preliminary fit. Table 3 shows that the error variances of the items ranged from 0.54 to $0.66(p<0.001)$ and the standard errors ranged from 0.04 to 0.06 . Establishing convergent validity requires examining the significance of the factor loadings (Anderson \& Gerbing, 1988). All item factor loadings were significant $(p<0.001)$ and ranged from 0.73 to 0.81 , confirming convergent validity (see Table 3 ).

Overall model fit. The overall model fit indices are outlined as follows: $\chi^{2} / d f=4.86$, critical $\mathrm{N}(\mathrm{CN})=$ 215, goodness-of-fit index $(\mathrm{GFI})=0.95$, adjusted GFI $(\mathrm{AGFI})=0.93$, Tucker-Lewis index $(\mathrm{TLI})=0.96$, normed fit index $(\mathrm{NFI})=0.96$, comparative fit index $(\mathrm{CFI})=0.97$, relative fit index $(\mathrm{RFI})=0.95$, standardized root mean square residual $(\mathrm{SRMR})=0.03$, root mean square error of approximation $($ RMSEA $)=0.07$, parsimony normed fit index $(\mathrm{PNFI})=0.75$, parsimony goodness of fit index $(\mathrm{PGFI})=0.62$, and parsimony 
comparative fit index $(\mathrm{PCFI})=0.76$. Furthermore, the $\chi^{2}$ test was significant $\left(\chi^{2}=209.4 ; d f=43 ; p<0.001\right)$. The fit indices indicated that the CTES demonstrated a favorable fit with the model (see Table 4).

Table 3

Estimates for the CTES

\begin{tabular}{|c|c|c|c|c|c|c|c|}
\hline & & $\begin{array}{l}\text { Standardized } \\
\text { factor loading }\end{array}$ & $\begin{array}{l}\text { Individual } \\
\text { item reliability }\end{array}$ & $\begin{array}{l}\text { Standard } \\
\text { error }\end{array}$ & $\begin{array}{l}\text { Error } \\
\text { variance }\end{array}$ & $\begin{array}{l}\text { Composite } \\
\text { reliability }\end{array}$ & $\begin{array}{l}\text { Average } \\
\text { variance } \\
\text { extracted }\end{array}$ \\
\hline \multirow{5}{*}{ Student discipline } & Item 1 & $0.74^{* * * k}$ & 0.55 & - & $0.55^{* 0 * k}$ & \multirow{5}{*}{0.83} & \multirow{5}{*}{0.50} \\
\hline & Item 2 & $0.80^{* * * * *}$ & 0.64 & 0.05 & $0.64^{* * * * *}$ & & \\
\hline & Item 3 & $0.79^{* 0 * k}$ & 0.62 & 0.06 & $0.62^{\text {*wok }}$ & & \\
\hline & Item 4 & $0.81^{* * * * *}$ & 0.66 & 0.05 & $0.66^{* * * *}$ & & \\
\hline & Item 5 & $0.73^{* * * *}$ & 0.53 & 0.05 & $0.54^{* * * *}$ & & \\
\hline \multirow{6}{*}{ Instructional strategies } & Item 6 & $0.75^{* \text { *w* }}$ & 0.56 & - & $0.57^{* * * *}$ & \multirow{6}{*}{0.86} & \multirow{6}{*}{0.50} \\
\hline & Item 7 & $0.74^{* 0 * 4}$ & 0.55 & 0.05 & $0.55^{* * * *}$ & & \\
\hline & Item 8 & $0.77^{* * * * *}$ & 0.59 & 0.05 & $0.59^{* * *}$ & & \\
\hline & Item 9 & $0.81^{* 0 * k}$ & 0.66 & 0.04 & $0.65^{* * * *}$ & & \\
\hline & Item 10 & $0.80^{* * * *}$ & 0.64 & 0.05 & $0.63^{* * 0 *}$ & & \\
\hline & Item 11 & $0.76^{\text {*ak }}$ & 0.58 & 0.05 & $0.58^{* * *}$ & & \\
\hline
\end{tabular}

Note. ${ }^{* * *} p<0.001$.

Table 4

Model Fit Summary of the Goodness-of-Fit Statistics for the CTES

\begin{tabular}{llc}
\hline Overall model fit indices & Criteria & Values \\
\hline$\chi^{2} / d f$ & $<5$ & 4.86 \\
GFI & $>0.90$ & 0.95 \\
AGFI & $>0.90$ & 0.93 \\
SRMR & $<0.05$ & 0.03 \\
RMSEA & $<0.08$ & 0.07 \\
TLI & $>0.90$ & 0.96 \\
NFI & $>0.90$ & 0.96 \\
CFI & $>0.90$ & 0.97 \\
RFI & $>0.90$ & 0.95 \\
CN & $>200$ & $215(\alpha=0.05)$ \\
PNFI & $>0.50$ & 0.75 \\
PGFI & $>0.50$ & 0.62 \\
PCFI & $>0.50$ & 0.76 \\
\hline
\end{tabular}

Fit of the internal structural model. The reliability of the individual CTES items ranged from 0.53 to 0.66 , and the composite reliability of each dimension was greater than 0.80 . The average variance extracted for each dimension was 0.50 (see Table 3). These results showed that the CTES exhibited adequate construct reliability and convergent validity.

\section{Descriptive Statistics for the CTES and TSES}

The means for the two dimensions of the CTES were 3.80 (student discipline) and 3.76 (instructional strategies). These results revealed that the elementary school teachers had positive perceptions about the efficacy of their student discipline and of the instructional strategies as a whole in their respective schools. The means of the three dimensions of the TSES were 4.17 (efficacy of classroom management), 3.77 (efficacy of 
student engagement), and 3.97 (efficacy of instructional strategies). These results indicated that the elementary school teachers perceived themselves as having some impact on their classroom management, student engagement, and instructional strategies (see Table 5).

Table 5

Means and Standard Deviations for the CTES and TSES $(N=758)$

\begin{tabular}{lclll}
\hline Dimension & Items & Sum & Standard deviation & Mean \\
\hline Collective teacher efficacy & 11 & 41.53 & 5.51 & 3.78 \\
Student discipline & 5 & 19.00 & 2.67 & 3.80 \\
Instructional strategies & 6 & 22.53 & 3.17 & 3.76 \\
Teacher self-efficacy & 12 & 47.69 & 4.97 & 3.97 \\
Efficacy of classroom management & 4 & 16.69 & 1.97 & 4.17 \\
Efficacy of student engagement & 4 & 15.09 & 2.08 & 3.77 \\
Efficacy of instructional strategies & 4 & 15.91 & 1.90 & 3.97 \\
\hline
\end{tabular}

\section{Relationships Between the CTES and TSES}

Scores for student discipline, instructional strategies, and the overall CTES were all positively and significantly correlated with the scores for classroom management, student engagement, instructional strategies, and the overall TSES $(0.22<r<0.44)$. All but one of the positive correlations was statistically significant $(p<$ 0.01 ). These results indicated that collective teacher efficacy was positively associated with teacher self-efficacy (see Table 6).

Table 6

Pearson Product-Moment Correlations for the CTES and TSES

\begin{tabular}{llll}
\hline \multirow{2}{*}{ Teacher self-efficacy } & \multicolumn{3}{c}{ Collective teacher efficacy } \\
\cline { 2 - 4 } & Student discipline & Instructional strategies & Total \\
\hline Classroom management & $0.29^{* *}$ & $0.22^{* *}$ & $0.27^{* *}$ \\
Student engagement & $0.39^{* *}$ & $0.36^{* *}$ & $0.40^{* *}$ \\
Instructional strategies & $0.37^{*}$ & $0.44^{* *}$ & $0.43^{* *}$ \\
Total & $0.42^{* *}$ & $0.40^{* *}$ & $0.43^{* *}$ \\
\hline
\end{tabular}

Notes. ${ }^{*} p<0.05 ;{ }^{* *} p<0.01$.

\section{Discussion}

\section{CTES Is a Reliable and Valid Measure of Student Discipline and Instructional Strategies}

Although numerous studies have applied exploratory factor analysis for examining CTES, fewer studies have applied confirmatory factor analysis to such measures. The main purpose of the current study was to develop a CTES for elementary school teachers. For a robust instrument of CTES, first, we conducted a thorough literature review and applied a concept clarification process. Second, we administered a questionnaire survey to a pilot sample of 232 elementary school teachers in Taiwan. After item analysis, exploratory factor analysis and reliability analysis were conducted, an 11-item formal CTES was constructed (Cronbach's $\alpha=$ 0.92). It comprised two subscales: student discipline (Cronbach's $\alpha=0.89$ ) and instructional strategies (Cronbach's $\alpha=0.82$ ). The explained variance for the total scale was $54.29 \%$.

A total of 758 valid participants were recruited for the formal test. We conducted a confirmatory factor analysis and observed that individual item reliabilities ranged from 0.53 to 0.66 , standardized factor loadings ranged from 0.73 to 0.81 , composite reliability was greater than 0.80 , and the average variance extracted was 
greater than 0.50. The fit indices (e.g., NFI, CFI, and RMSEA) revealed that the CTES exhibited an optimal fit with the model, signifying that it is a reliable and valid measure of student discipline and instructional strategies. The CTES can thus be offered to educators seeking to evaluate elementary school teachers' collective teacher efficacy and serve as a basis for further research.

\section{Elementary School Homeroom Teachers Reported Positive Self-Efficacy and Collective Efficacy, but the Variability of Collective Efficacy Was Greater Than That of Self-Efficacy}

The means of the subscales of the TSES ranged from 3.97 to 4.17, and those of the CTES subscales ranged from 3.76 to 3.80. These results indicated that the elementary homeroom teachers perceived themselves to have positive teacher self-efficacy and all the teachers in the schools to have positive collective teacher efficacy.

In Taiwan, each elementary school homeroom teacher teaches several subjects. Other teachers teach special subjects (usually music, art, science, or physical education) to a number of different classes at different times. Elementary school teachers must be knowledgeable about instructional strategies for the various subjects they teach and must create a classroom environment favorable to learning and personal growth while motivating their students and establishing an effective rapport with them.

The role of an elementary school teacher is similar to that of a parent at home. In Taiwanese culture, this role incorporates authority and dignity. In addition to teaching the subject matter, elementary school teachers must promote personal development and foster normative behavior in their students while providing them with the tools to navigate social and cultural situations (Hsieh, Lin, Chao, \& Wang, 2009). Therefore, elementary homeroom teachers believe that they can influence student engagement, instructional practices, and classroom management, and that the teachers in the school collectively can influence student discipline and instructional strategies.

In our study, the standard deviations for the TSES subscales ranged from 1.90 to 2.08 , and those for the CTES subscales ranged from 2.67 to 3.17. The standard deviations were higher for the CTES than they were for the TSES. Collective teacher efficacy is based on the individually perceived capabilities of the group as a whole (Lim \& Eo, 2014), but it is not a monolithic group attribute; it can vary among its members, even if they belong to the same group. Also, belief in the commonality of efficacy does not guarantee that every member of the group holds the same viewpoints on all aspects of group functioning (Bandura, 1997). This explains why the variability of elementary school homeroom teachers' perceptions about the teachers' collective efficacy was greater than their perceptions about their self-efficacy. Accordingly, the question of how to increase collective teacher efficacy is vital.

\section{Collective Teacher Efficacy Was Significantly Positively Related to Teacher Self-Efficacy}

In this study, all the statistically significant correlations of the CTES subscales with the TSES subscales were low to medium in magnitude. Therefore, our hypothesis was supported, which is consistent with previous studies (e.g., Calik et al., 2012; Gibbs \& Powell, 2012; Goddard \& Goddard, 2001). According to social cognitive theory, collective efficacy is rooted in self-efficacy (Bandura, 1997), and an individual teacher's self-efficacy is possibly based on how effectively the team functions as a whole (Skaalvik \& Skaalvik, 2007).

Chiang's (2014) qualitative data analysis revealed that a high level collective teacher efficacy is considered the norm and is honored in Taiwanese schools. It is encouraged as a strategy to promote teachers' self-efficacy and improves their teaching behavior. In Taiwan, one elementary school homeroom teacher and several special subject teachers team up to cover a class and share responsibility for the class. Homeroom 
teachers have to work closely with special subject teachers to ensure that their students achieve their full potential at school. This explains the observed significant positive correlation between collective teacher efficacy and teacher self-efficacy.

\section{Conclusion}

This study was a theoretical and empirical analysis of the development of the CTES. First, a model for the CTES was constructed for use in elementary schools. Subsequently, the CTES was developed, tested, and determined to demonstrate strong reliability and reasonable validity. Finally, the application of the CTES and TSES to examine the perceptions of school teachers perceived themselves to have positive teacher self-efficacy and positive collective teacher efficacy in their schools. The variability of teachers' collective efficacy was greater than that of their self-efficacy. In addition, collective teacher efficacy was positively correlated with teacher self-efficacy.

Because we tested only elementary school homeroom teachers in Taiwan, the generalizability of our findings to other teachers may be limited. To increase external validity, studies involving different samples should be conducted. The practical implication of the positive correlation between the CTES and the TSES that various strategies can be adopted for enhancing both factors. For example, principals, as a transformational leader, should empower teachers to achieve the collective task of school through the development of self-efficacy (Demir, 2008).

\section{References}

Abu-Tineh, A. M., Khasawneh, S. A., \& Khalaileh, H. A. (2011). Teacher self-efficacy and classroom management styles in Jordanian schools. Management in Education, 25(4), 175-181.

Anderson, J. C., \& Gerbing, D. W. (1988). Structural equation modeling in practice: A review and recommended two-step approach. Psychological Bulletin, 103(3), 411-423.

Bagozzi, R. P., \& Yi, Y. (1988). On the evaluation of structural equation models. Academy of Marketing Science Journal, 16(1), 74-94.

Bandura, A. (1977). Self-efficacy: Toward a unifying theory of behavioral change. Psychological Review, 84, 191-215.

Bandura, A. (1986). Social foundations of thought and action: A social cognitive theory. Englewood Cliffs, N.J.: Prentice-Hall, Inc..

Bandura, A. (1997). Self-efficacy: The exercise of control. New York, N.Y.: W. H. Freeman.

Bandura, A. (2000). Exercise of human agency through collective efficacy. Current Directions in Psychological Science, 9(3), 75-78.

Barr, M. F. (2002). Fostering student achievement: A study of the relationship of collective teacher efficacy and student achievement. Dissertation Abstracts International, 63(02), 475A.

Calik, T., Sezgin, F., Kavgaci, H., \& Cagatay Kilinc, A. (2012). Examination of relationships between instructional leadership of school principals and self-efficacy of teachers and collective teacher efficacy. Education Sciences: Theory and Practice, $12(4), 2498-2504$.

Chen, C. W. (2009). The relationship between teacher's self-efficacy and collective teacher efficacy in junior high schools: An application of hierarchical linear modeling (Unpublished master's thesis, National Changhua University of Education, Taiwan).

Chen. C. W. (2010). The relationship among collective teacher efficacy, teacher self-efficacy and organizational citizenship behavior among junior high school teachers: An analysis of multilevel mediation. Contemporary Educational Research Quarterly, 18(2), 29-69.

Chen, C. W., \& Wu, P. J. (2010). The relationship between teacher self-efficacy and collective teacher efficacy among junior high school teachers. Educational Policy Forum, 13(3), 127-154.

Chiang, C. H. (2014). The relationship among collective teacher efficacy, teacher self-efficacy and teaching behaviors among elementary school homeroom teachers (Unpublished doctoral dissertation, National Sun Yat-Sen University, Taiwan). 
Ciani, K. D., Summers, J. J., \& Easter, M. A. (2008). A “top-down” analysis of high school teacher motivation. Contemporary Educational Psychology, 33(4), 533-560.

Demir, K. (2008). Transformational leadership and collective efficacy: The moderating roles of collaborative culture and teachers' self-efficacy. Eurasian Journal of Educational Research, 33, 93-112.

Fives, H., \& Looney, L. (2009). College instructors' sense of teaching and collective efficacy. International Journal of Teaching and Learning in Higher Education, 20(2), 182-191.

Gibbs, S., \& Powell, B. (2012). Teacher efficacy and pupil behavior: The structure of teachers' individual and collective beliefs and their relationship with numbers of pupils excluded from school. British Journal of Educational Psychology, 82(4), 564-584.

Gibson, S., \& Dembo, M. H. (1984). Teacher efficacy: A construct validation. Journal of Educational Psychology, 76, 569-582.

Goddard, R. D. (1999). The effect of collective teacher efficacy on student achievement in urban public elementary schools. Retrieved from http://rave.ohiolink.edu/etdc/view?accnum=osu1241095125

Goddard, R. D. (2002). A theoretical and empirical analysis of the measurement of collective efficacy: The development of a short form. Educational and Psychological Measurement, 62, 97-100.

Goddard, R. D., \& Goddard, Y. L. (2001). A multilevel analysis of the relationship between teacher and collective efficacy in urban schools. Teaching and Teacher Education, 17, 807-818.

Goddard, R. D., Hoy, W. K., \& Hoy, A. W. (2000). Collective teacher efficacy: Its meaning, measure, and impact on student achievement. American Educational Research Journal, 37, 479-507.

Goddard, R. D., Hoy, W. K., \& Hoy, A. W. (2004). Collective efficacy beliefs: Theoretical developments, empirical evidence, and future directions. Educational Researcher, 31, 3-13.

Hsiao, H. C., Chang, J. C., Tu, Y., \& Chen, S. (2011). The influence of teachers' self-efficacy on innovative work behavior. Retrieved from http://www.ipedr.com/vol5/no1/50-H00112.pdf

Hsieh, F. J., Lin, P. J., Chao, G., \& Wang, T. Y. (2009). Policy and practice of mathematics teacher education in Taiwan. Retrieved from http://tedsm.math.ntnu.edu.tw/Teds-m\%20Taiwan\%20Policy\%20Report.pdf

Hsu, W. C. (2008). The relationships between teacher efficacy and retirement attitudes among elementary school middle-aged teachers in central Taiwan (Unpublished master's thesis, National Changhua University of Education, Taiwan).

Hung, F. H. (2010). A study of the relationships among high school teachers' and students' group cohesion, collective efficacy and self efficacy. Journal of Taipei College of Maritime Technology, 3(1), 93-110.

Hung, F. Y., Chiou, S. Y., \& Huang, T. H. (2012). The measurement and structure verification of high school teachers' collective teacher efficacy scale. National Chiayi University Journal of the Educational Research, 28, 35-58.

Lee, J. C. K., Zhang, Z., \& Yin, H. (2011). A multilevel analysis of the impact of a professional learning community, faculty trust in colleagues and collective efficacy on teacher commitment to students. Teaching and Teacher Education, 27(5), 820-830.

Lim, S., \& Eo, S. (2014). The mediating roles of collective teacher efficacy in the relations of teachers' perceptions of school organizational climate to their burnout. Teaching and Teacher Education, 44, 138-147.

Magno, C., \& Sernbrano, J. (2007). The role of teacher efficacy and characteristics on teaching effectiveness, performance, and use of learner-centered practices. Asia-Pacific Education Researcher, 16(1), 73-90.

Moolenaar, N. M., Sleegers, P. J. C., \& Daly, A. J. (2012). Teaming up: Linking collaboration networks, collective efficacy, and student achievement. Teaching and Teacher Education, 28, 251-262.

Rahimi, A., \& Gheitasi, P. (2010). The interface between English teachers' sense of efficacy and their feedback on learners' writing, and learners' writing achievement. Procedia Social and Behavioral Sciences, 5, 1932-1938.

Ross, J. A., \& Gray, P. (2006) Transformational leadership and teacher commitment to organizational values: The mediating effects of collective teacher efficacy. School Effectiveness and School Improvement, 17(2), 179-199.

Skaalvik, E. M., \& Skaalvik, M. (2007). Dimensions of teacher self-efficacy and relations with strain factors, perceived collective teacher efficacy, and teacher burnout. Journal of Educational Psychology, 99, 611-625.

Tschannen-Moran, M., \& Barr, M. F. (2004). Fostering student learning: The relationship of collective teacher efficacy and student achievement. Leadership and Policy in Schools, 3, 189-209.

Tschannen-Moran, M., \& Hoy, A. W. (2001). Teacher efficacy: Capturing an elusive construct. Teaching and Teacher Education, 17, 783-805.

Tschannen-Moran, M., Hoy, A. W., \& Hoy, W. K. (1998). Teacher efficacy: Its meaning and measure. Review of Educational Research, 68, 202-248. 